\title{
O DEBATE SOBRE O PEDIDO DE IMPEACHMENT DE BOLSONARO: POLÊMICA, ARGUMENTAÇÃO E ESTRATÉGIAS DE TEXTUALIZAÇÃO
}

\section{THE DEBATE ABOUT BOLSONARO'S IMPEACHING REQUEST: POLEMIC, ARGUMENTATION AND TEXTUALIZATION STRATEGIES}

\author{
Bharbara Bonelle de Sousa ${ }^{1}$ \\ Gabriela Malini de Aguiar ${ }^{2}$ \\ Rivaldo Capistrano Júnior ${ }^{3}$
}

\begin{abstract}
RESUMO: Propomos neste artigo uma discussão sobre como a polêmica em sua vertente argumentativa (AMOSSY, 2017) se materializa e se atualiza em comentários (postagens reativas) da rede social Facebook. Para tanto, selecionamos, na página UOL do Facebook, no dia 17 de março de 2021, a Webnotícia "OPOSIÇÃO ENTREGA PEDIDO IMPEACHMENT DE BOLSONARO À CÂMARA DE DEPUTADOS e constituímos como objeto de análise dezesseis (16) comentários a essa postagem motivadora. Desse modo, considerando a relevância de fenômenos textuais para a investigação da polêmica em sua vertente argumentativa (CAVALCANTE et al., 2020, 2021), elegemos como categorias analíticas a referenciação e a intertextualidade. Com base nas análises empreendidas, podemos concluir que referentes (objetos de discurso) e as relações intertextuais i) contribuem para a instauração, manutenção e atualização da interação polêmica e ii) constituem-se, no jogo polêmico, em relevantes estratégias de violência verbal, reforçando o caráter dicotômico da polêmica.
\end{abstract}

PALAVRAS-CHAVE: Argumentação polêmica. Referenciação. Intertextualidade. Comentários do Facebook.

ABSTRACT: We propose in this article a discussion on how the polemic in its argumentative aspect (AMOSSY, 2017) materializes and is actualized in comments (reactive posts) of the social network Facebook. To do so, we selected, on the UOL page, on March 17, 2021, the Webnotice "OPPOSITION SENDS REQUEST FOR IMPEACHMENT OF BOLSONARO TO THE CHAMBER OF DEPUTES, and constituted as object of analysis sixteen (16) comments to this motivating post. Thus, considering the relevance of textual phenomena for the investigation of controversy in its argumentative aspect (CAVALCANTE et al., 2020, 2021), we chose referencing and intertextuality as analytical categories. Based on the analysis undertaken, we can conclude that referents (objects of discourse) and intertextual relations i) contribute to the establishment, maintenance and updating of the polemical interaction and ii) constitute, in the

\footnotetext{
${ }^{1}$ Doutoranda do Programa de Pós-Graduação em Linguística da Universidade Federal do Espírito Santo, Centro de Ciências Humanas e Naturais, Vitória, Espírito Santo, Brasil. E-mail: bharbara bonelles@hotmail.com

${ }^{2}$ Graduanda em Letras Português-Espanhol na Universidade Federal do Espírito Santo, Centro de Ciências Humanas e Naturais, Vitória, Espírito Santo, Brasil. E-mail: gabrielamalinideaguiar@hotmail.com

${ }^{3}$ Docente do Departamento de Línguas e Letras e do Programa de Pós-Graduação em Linguística (UFES), Vitória, ES, Brasil. E-mail: r.capistrano@uol.com.br.
} 


\section{PERcursos Linguísticos • Vitória (ES) •v. $11 \bullet$ •n. 29 • 2021 • ISSN: 2236-2592 • Dossiê temático $\bullet O$ texto na pesquisa e no ensino: conhecimentos, práticas e desafios na contemporaneidade •}

polemical game, relevant strategies of verbal violence, reinforcing the dichotomous nature of the polemic.

KEYWORDS: Polemic argumentation. Referencing. Intertextuality. Facebook comments.

\section{Introdução}

De acordo com Amossy (2017), as redes sociais digitais constituem-se num espaço de discussões de temas de interesse da sociedade, o que muito favorece o surgimento de controvérsias e, consequentemente, de interações conflituosas. Desse modo, buscamos analisar interações polêmicas em comentários da rede social digital Facebook. Para isso, elegemos como tema da postagem motivadora a Webnotícia "Oposição entrega pedido de impeachment de Bolsonaro à Câmara de Deputados", vinculada na página do UOL Notícias, e, como corpus de análise, comentários (postagens reativas) feitos a essa postagem.

O tema da postagem motivadora mostra-se controverso e relevante para a análise da modalidade argumentativa polêmica (AMOSSY, 2017), uma vez que coloca no centro das interações a polarização entre opositores e bolsonaristas (simpatizantes de Bolsonaro).

Como base teórico-metodológica, elegemos estudos sobre a argumentação, mais especificamente, da modalidade polêmica (AMOSSY, 2017; CAVALCANTE et al 2020), sobre a violência verbal (CABRAL, 2019 , 2018) e sobre a referenciação (KOCH e ELIAS, 2016; CAVALCANTE et al., 2017) e a intertextualidade (CAVALCANTE et al., 2021).

$\mathrm{Na}$ interface estabelecida, assumimos que fenômenos textuais, tais como a referenciação e a intertextualidade, são motivados por uma tentativa de explicar como o sujeito age sobre o seu dizer, reelaborando-o a todo instante, negociando-o com os prováveis interlocutores, para buscar atender a seus propósitos e que os diferentes modos como os textos se repetem uns nos outros atuam como vetor para que se construa pontos de vistas e sua relação com crenças, valores e posicionamentos. (CAVALCANTE et al., 2020).

Organizamos o trabalho em quatro seções. Na primeira seção, discutimos a função estratégica da argumentação na modalidade polêmica. Na segunda, tratamos da referenciação e da intertextualidade, com base nos pressupostos da Linguística Textual (LT), e destacamos suas funções argumentativas. Finalmente, na terceira, analisamos comentários do Facebook e buscamos evidenciar a função da atividade referencial e da intertextualidade no gerenciamento verbal de conflitos polêmicos. 


\section{PERcursos Linguísticos • Vitória (ES) •v. $11 \bullet$ n. 29 • 2021 • ISSN: 2236-2592 • Dossiê temático $\bullet O$ texto na pesquisa e no ensino: conhecimentos, práticas e desafios na contemporaneidade •}

\section{Polêmica como modalidade argumentativa}

Todo discurso é um ato de linguagem (CHARAUDEAU, 2015), baseado no princípio de alteridade (ato de linguagem se realiza numa troca com outro, não há "eu" sem "tu"), de influência (busca-se atingir o interlocutante) e de regulação (os parceiros procedem à regulação do jogo de influências). Dessa forma, existe uma espécie de polemicidade que é constitutiva do discurso, bem como uma argumentatividade que lhe é intrínseca, pois todo discurso carrega determinados valores axiológicos e certos posicionamentos a ele associados.

Nessa perspectiva, Amossy (2011), ao estudar a argumentação nos discursos, abandona a noção estritamente retórica, na qual a figura do locutor tinha um papel determinante na adesão do auditório a uma tese, e passa uma "concepção mais larga de argumentação, entendida como a tentativa de modificar, de reorientar, ou mais simplesmente, de reforçar, pelos recursos da linguagem, a visão das coisas da parte do alocutário.” (AMOSSY, 2011, p. 130)

A autora sugere que as práticas discursivas sejam analisadas em um continuum de argumentatividade em que os discursos, integrados em práticas sociais, apresentam uma dimensão argumentativa a eles associada e que poucos discursos têm realmente uma visada argumentativa, uma vez que empregam o modo persuasivo de argumentar.

Nesse sentido, a argumentatividade é inerente ao discurso. Frequentemente, tenta-se persuadir um auditório a aderir a uma tese, modificando a orientação do modo particular de ver as coisas. Assim, diz-se que há uma visada argumentativa quando o objetivo é convencer o locutor e uma dimensão argumentativa quando se tem a intenção de orientá-lo.

Diferentemente da concepção retórica de argumentação que visava influenciar os modos de pensar e de ver pela utilização do discurso, com vistas ao acordo, conforme PERELMAN E OLBRECHTS-TYTECA ([1970], 2020), AMOSSY $(2008,2017)$ defende que todo discurso busca, ao menos, orientar os modos de ver e de pensar do auditório e, assim, influenciá-lo.

Diz-se, então, que a concepção de argumentação de Amossy (2008) é modular e varia num continuum, podendo os textos apresentar diferentes possibilidades de modalidade argumentativa. Por modalidades argumentativas, entende-se como sendo os "tipos de troca argumentativa que, atravessando os gêneros do discurso, modelam a forma como a argumentação funciona num quadro tanto dialogal quanto dialógico" (AMOSSY, 2008, p. 232). Em vista disso, há diferentes formas de estrategicamente tentar influenciar o outro. 


\section{PERcursos Linguísticos • Vitória (ES) •v. 11 •n. 29 • 2021 • ISSN: 2236-2592 • Dossiê temático $\bullet O$ texto na pesquisa e no ensino: conhecimentos, práticas e desafios na contemporaneidade •}

Essas diferentes maneiras de argumentar são caracterizadas com base nos seguintes parâmetros: i) os papéis desempenhados pelos participantes no dispositivo enunciativo (parceiros, adversários); ii) a maneira pela qual ocorre a tentativa de persuasão (apaixonada, racional, colaborativa, instrutiva); e iii) o modo como o interlocutor é concebido (ser de razão e/ ou de sentimento, aluno ou discípulo, cúmplice ou rival etc.). Amossy (2008.p. 233-234) apresenta algumas possíveis modalidades, apontando gêneros do discurso que as privilegiam, conforme elencamos a seguir:

a) Modalidade demonstrativa: é aquela em que o locutor busca a adesão do(s) interlocutor(es) apresentando uma tese/ uma opinião, em um discurso monogerido ou dialogal, com base em raciocínio apoiado em provas. São exemplos de gêneros nos quais essa modalidade é recorrente: o editorial, o artigo de opinião, o debate eleitoral, etc.;

b) Modalidade patêmica: é a modalidade caracterizada fundamentalmente pelo apelo explícito aos sentimentos do auditório para angariar sua adesão à tese ou ao ponto de vista apresentado. Estes gêneros privilegiam a modalidade patêmica: o apelo à ajuda humanitária, o poema lírico, a declaração de amor, entre outros;

c) Modalidade pedagógica: é a da transmissão de um saber por um locutor autorizado a fazê-lo a um auditório que se encontra na condição de aprendiz. O modo de manifestação dessa troca também pode ser, como nas modalidades anteriores, monogerido ou poligerido. Gêneros como o manual escolar, a aula, a palestra, a história de literatura infantil, entre outros, são exemplos prototípicos de ocorrência dessa modalidade;

d) Modalidade de coconstrução: é aquela em que os participantes levantam conjuntamente uma questão e, da mesma forma, buscam resolvê-la, por meio de uma interação dialogal. A reunião profissional, a reunião de colegiado, a conversação familiar são exemplos de gêneros que privilegiam essa modalidade;

e) Modalidade negociada: é o tipo de troca em que os participantes debatem sobre um problema que os divide, mas para o qual estão dispostos a buscar e a estabelecer um acordo, por meio de uma negociação das divergências. As negociações comerciais, as trocas diplomáticas, as audiências de conciliação, entre outros, são gêneros que privilegiam a modalidade negociada;

f) Modalidade polêmica: caracteriza-se pela confrontação de teses antagônicas, em que se tenta desacreditar o opositor, mas também se tenta atingir o terceiro, que acompanha a interação à distância. Gênero como os comentários on-line, os debates são característicos da modalidade polêmica. 


\section{PERcursos Linguísticos • Vitória (ES) •v. $11 \bullet$ n. 29 • 2021 • ISSN: 2236-2592 • Dossiê temático $\bullet O$ texto na pesquisa e no ensino: conhecimentos, práticas e desafios na contemporaneidade •}

A modalidade polêmica foi a única das seis a receber de Amossy (2017) um tratamento metodológico especifico. Tratamos dela na próxima seção.

\section{A polêmica no espaço público}

A polêmica é um debate em torno de uma questão da atualidade, de interesse público, que comporta os anseios da sociedade mais ou menos importantes numa dada cultura (AMOSSY, 2017, p.49). A primeira marca da polêmica como debate da atualidade está na oposição de discurso. Esse antagonismo de opiniões é a condição essencial para a instauração da polêmica.

Essa condição supõe um debate que permite a cada um expor e defender seu ponto de vista, refutando e desqualificando o ponto de vista do outro. Essa condição se enquadra na retórica argumentativa. Assim, argumentamos quando temos um desacordo de opiniões, fazendo com que cada um justifique seu posicionamento.

Nesse contexto, de acordo com Amossy (2017), a polêmica intensifica o confronto que dá origem à atividade argumentativa. Em outras palavras, a polêmica é caracterizada como uma modalidade argumentativa construída pela retórica do dissenso, emergindo de eventos concretos, únicos e irrepetíveis.

Nessa modalidade argumentativa, caracterizada como uma interação fortemente antagonista que atravessa os gêneros e discursos atuam um Proponente e um Opositor, cujos propósitos não são convencer-se mutuamente, mas atrair a adesão de um Terceiro, que é levado a aderir ao ponto de vista, e não o adversário; assim a polêmica tem também por função atrair a adesão do Terceiro (AMOSSY, 2017).

Portanto, os traços que colocam a polêmica numa ancoragem conflitual se traduzem pela dicotomização, pela polarização e pela desqualificação do outro, e de forma secundária, pela violência verbal, e pelo pathos (emoção).

Nesse contexto, a primeira característica da polêmica é o choque de opiniões dicotômicas. Se há opiniões contraditórias é porque há uma dicotomização de posições. Enquanto no debate tenta-se chega a uma possível solução, a dicotomização torna o debate difícil, às vezes impossível de se resolver. Assim, a busca pelo acordo nem sempre é possível. Isso quer dizer que, em sociedades democráticas pluralistas, a polêmica preenche funções sociais importantes, 


\section{PERcursos Linguísticos • Vitória (ES) •v. $11 \bullet$ •n. 29 • 2021 • ISSN: 2236-2592 • Dossiê temático $\bullet O$ texto na pesquisa e no ensino: conhecimentos, práticas e desafios na contemporaneidade •}

precisamente em razão do que é geralmente criticado nela: uma gestão verbal do conflito realizada sob o modo de dissensão. (AMOSSY, 2017, p. 12)

Na polêmica há também uma distinção entre os actantes e os atores, havendo uma operação de polarização. A polarização, segunda característica da polêmica, se difere da dicotomização, pois, enquanto uma exacerba as oposições até torná-las inconciliáveis, a polarização realiza agrupamentos em campos adversos entre participantes, ela é de ordem social.

A polarização provoca um movimento de reagrupamento por identificação, e para se consolidar apresenta de forma pejorativa os outros. Ela supõe um inimigo em comum e tem como estratégia a subversão, fazer o outro levar o descrédito, definindo-o como um defensor de um ponto de vista caracterizado por sua má-fé e más intenções. Essa desqualificação da tese outro se configura como a terceira característica definidora da modalidade polêmica.

O discurso polêmico é um discurso desqualificador que gera o descrédito do adversário e o discurso que ele presumidamente sustenta. A desqualificação do outro pode ser compreendida sob duas formas: uma centrada no logos e outra, no ethos. Na primeira há uma tentativa em desmerecer o discurso do adversário pela inadmissibilidade de sua tese. Contudo, há uma necessidade de reconhecimento pelo auditório do discurso atacado pelo Proponente. Já a segunda maneira, centrada no ethos do Oponente, consiste em o Proponente depreciar o adversário atacando a sua imagem. (MACEDO e CAVALCANTE, 2019)

Assim, uma confrontação dicotomizada de teses antagônicas e a polarização que ela desencadeia supõem sujeitos profundamente implicados no debate. Isso quer dizer que o locutor coloca marcas de subjetividade no seu discurso e ele toma veemente uma posição afirmando, negando, interrogando, exclamando. A emoção no discurso é um resultado da implicação do locutor. O engajamento emocional se faz acompanhar de uma tentativa de tocar o coração dos leitores/espectadores.

O papel da emoção na polêmica deve ser revisto, assim como a questão da violência verbal. Amossy (2017) assegura que a violência verbal não uma condição suficiente, nem mesmo necessária para a instauração da polêmica, configurando-se mais como um acessório do que um traço definitório. À vista disso, a violência vernal se dá não como uma modalidade argumentativa, mas como um registro discurso. E assim, como o pathos manifesta e intensifica a dicotomização, a polarização e o descrétido que fundamentam os embates públicos.

Assim, nem toda violência verbal se configura como polêmica, pois não é uma condição essencial da polêmica, mas um traço opcional. Os procedimentos discursivos que criam uma impressão de violência verbal só se tornam polêmica quando são utilizados no contexto de 


\section{PERcursos Linguísticos • Vitória (ES) •v. $11 \bullet$ •n. 29 • 2021 • ISSN: 2236-2592 • Dossiê temático $\bullet O$ texto na pesquisa e no ensino: conhecimentos, práticas e desafios na contemporaneidade •}

uma confrontação de opiniões contraditórias. Assim, expressões avaliativas de desvalorização, como os insultos e ofensas se apresentam com meio de reforçar a visão negativa do outro, congelando-o no lado oposto, revelando traços de polarização do debate. (CABRAL, 2018)

Nessa perspectiva, as redes sociais digitais possuem um alto nível de trocas comunicativas por meio de comentários, favorecem a instaurações de interações polêmicas e possuem grande potencial para abordar as chamadas "discussões inflamadas". Esses espaços têm sido "palco para discussões violentas, de fortes controvérsias nas quais imperam discursos agressivos, cujos movimentos são marcados pela desqualificação do outro" (CABRAL, 2019, p.423).

Assim, alguns aspectos que configuram a interação ganham destaque nas estratégias de desqualificação do outro, que induzem, muitas vezes, à violência verbal em textos de ambientes digitais on-line, e, por conseguinte, nas interações polêmicas.

Convém ressaltar que a busca pelo acordo nem sempre é possível, pois, em sociedades democráticas pluralistas, essa busca ameaça a harmonia social, tendo em vista que "é, indubitavelmente, o conflito de opiniões que predomina no espaço democrático contemporâneo, o qual respeita a diversidade e a liberdade de pensamento e de expressão" (AMOSSY, 2017. p. $13)$.

Nesse sentido, o fato de ser uma "gestão verbal do conflito realizada sob o modo da dissensão" (AMOSSY, 2017. p. 12) faz com que a polêmica permita aos cidadãos viverem juntos sem apelar à violência física, gerindo o desacordo pela interação verbal.

De um modo geral, assumimos que a polêmica só pode ser examinada na interação, no acontecimento dos textos e também na forma como alguns deles evocam o saberes de outros. Portanto, é na interação e nas intertextualidades pressupostas que todos os atores da polêmica se colocam nos papéis sociais de Proponente, Oponente e Terceiro.

\section{Referenciação, intertextualidade e argumentação}

A argumentação é uma atividade presente em toda interação humana. Desse modo, os sujeitos das interações são tidos como entes discursivos que produzem textos a partir de posições determinadas institucionalmente, o que evidencia ser o uso da linguagem revelador das "relações que desejamos estabelecer, efeitos que pretendemos causar [...]", conforme defendem Koch e Elias (2016, p. 13).

No que diz respeito à inter-relação entre argumentação e referenciação, entendemos que, considerando os estudos de Koch e Elias (2016) e Cavalcante et al. (2020), a apresentação 


\section{PERcursos Linguísticos • Vitória (ES) •v. $11 \bullet$ •n. 29 • 2021 • ISSN: 2236-2592 • Dossiê temático $\bullet O$ texto na pesquisa e no ensino: conhecimentos, práticas e desafios na contemporaneidade •}

e a retomada de objetos de discurso (ou referentes) são realizadas negociadamente pelos sujeitos sociais em interações situadas, o que evidencia pontos de vista e assinala orientações argumentativas. Assim sendo, a referenciação é uma atividade argumentativa, e o referente (aquilo de que se vai tratar) é construído na argumentatividade, a partir do momento em que são introduzidos e retomados no texto (KOCH e ELIAS, 2016; CAVALCANTE et al., 2017).

Desse modo, a introdução referencial cumpre a função de apresentar o referente no texto, e as anáforas, por sua vez, retomam direta ou indiretamente o referente introduzido, mantendo-o e recategorizando-o (CAVALCANTE et al., 2017). Por sua vez, a dêixis, outro processo referencial, de acordo com Cavalcante (2012), aponta para a localização e a identificação de diversos aspectos (pessoas, objetos, eventos, processos).

Esses processos referenciais, como já dissemos, são decisivos para a orientação argumentativa (argumentatividade) que o sujeito intenciona imprimir ao texto, uma vez que os sujeitos operam diversas escolhas em relação ao que lhes parece ser a mais adequada ao seu projeto de dizer. Em outras palavras, os sujeitos marcam seus posicionamentos e orientam argumentativamente o locutor por meio de expressões nominais referenciais.

No que se refere à intertextualidade, assumimos o pressuposto sociocognitivo, como bem destaca Cavalcante (2021), de que há diversificados diálogos entre textos específicos, entre gêneros e marcas estilísticas autorais. Dessa maneira, tanto na produção quanto na recepção de um texto, os sujeitos recorrem ao conhecimento prévio de outros textos.

Nessa perspectiva, as diferentes formas com que os textos se repetem uns nos outros agem na construção de pontos de vistas e em sua relação com crenças, valores e posicionamentos. Assim, um texto de um determinado gênero pode fazer uma remissão a um fato já divulgado em textos anteriores, e, consequentemente pode trazer à tona uma dicotomização de teses ao abordar uma questão da atualidade, de interesse público. (CAVALCANTE et al., 2021).

Portanto, consoante Cavalcante et al (2020), assumimos que a modalidade polêmica nasce a partir das relações intertextuais, e só se efetiva na consideração do diálogo entre textos.

Dito isso, na próxima seção, passamos a analise de vinte comentários, extraídos da página do UOL do Facebook.

A interação polêmica em comentários do Facebook: uma proposta de análise 


\section{PERcursos Linguísticos • Vitória (ES) •v. $11 \bullet$ •n. 29 • 2021 • ISSN: 2236-2592 • Dossiê temático $\bullet O$ texto na pesquisa e no ensino: conhecimentos, práticas e desafios na contemporaneidade •}

Nosso corpus $^{4}$ foi veiculado na página UOL do Facebook. Trata-se da Webnotícia, intitulada "OPOSIÇÃO ENTREGA PEDIDO IMPEACHMENT DE BOLSONARO À CÂMARA DE DEPUTADOS".

Como os comentários eram muito numerosos, utilizamos dois critérios de seleção. $\mathrm{O}$ primeiro foi a seleção dos 20 (vinte) comentários mais recentes, na ocasião da coleta. Posteriormente, o segundo critério foi a seleção de comentários nos quais era evidente o uso de referentes (objetos de discurso) na confrontação de teses antagônicas e na desqualificação do opositor.

Dessa forma, chegamos a dezesseis (16) comentários, assim organizados textualmente: um $(01)$ comentário (C 1) com mais dois (02) comentários a comentário (CC 1.1 e CC 1.2$)$ e um (01) comentário (C 2) com mais doze (12) comentários a comentário (CC 2.1, CC 2.2, CC 2.3, CC 2.4, CC 2.5, CC 2.6, CC 2.7, CC 2.8, CC 2.9, CC 2.10, CC 2.11 e CC 2.12).

Figura 01: postagem motivadora

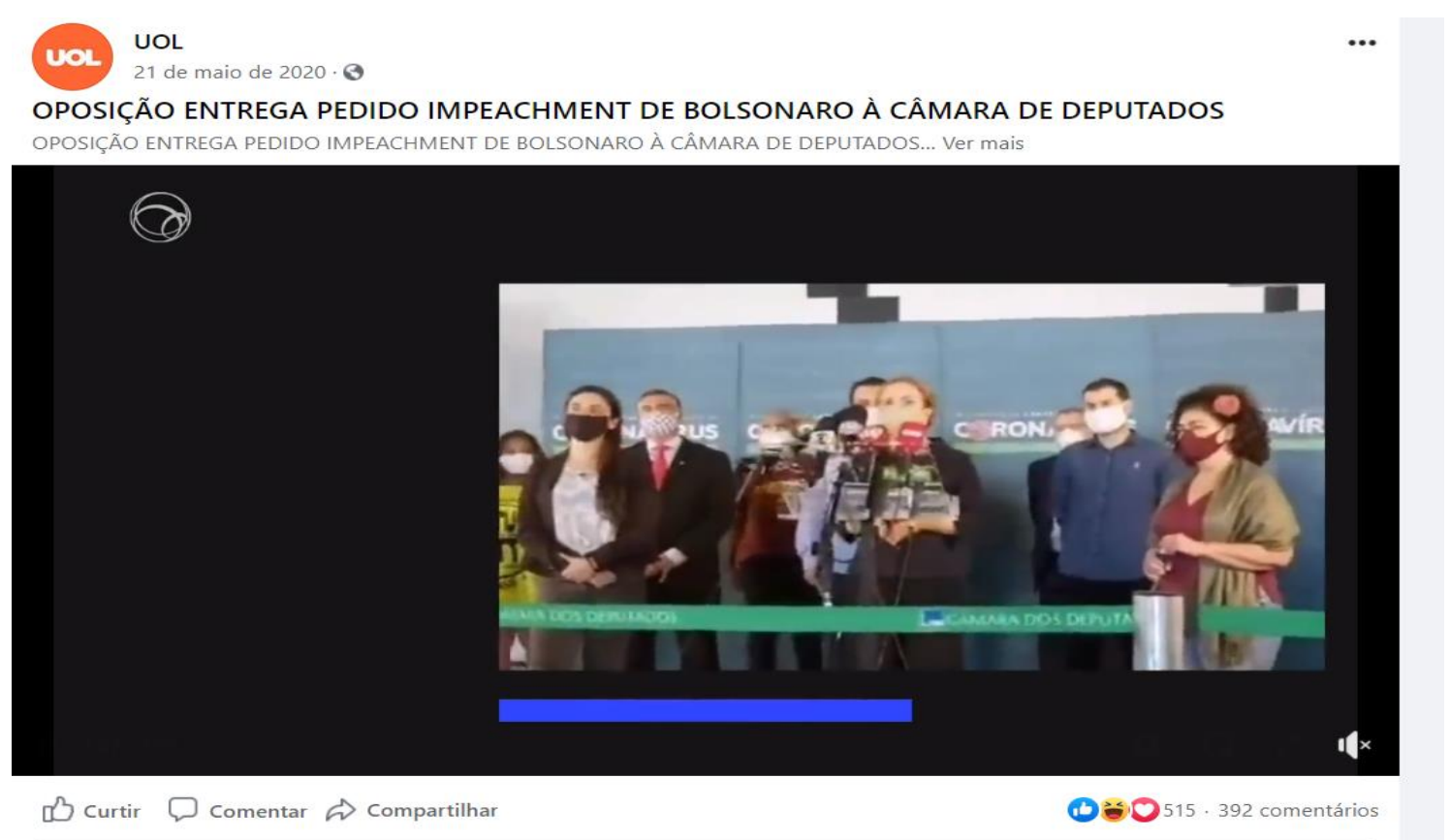

Fonte: https://www.facebook.com/21539158238/videos/2630608990540699/

Na figura 01, temos a Webnotícia, constituída por um título verbal escrito, “Oposição entre pedido de impeachment de Bolsonaro à Câmara de Deputados", e por um trecho de vídeo, com a duração de 2 minutos e 50 segundos, no qual Gleisi Hoffmann, Deputada e Presidente Nacional do Partido dos Trabalhadores (PT), questiona a competência do Presidente Jair

\footnotetext{
${ }^{4} \mathrm{O}$ corpus aqui analisado foi extraído da Pesquisa de Iniciação Científica, realizada por Gabriela Malini de Aguiar, bolsista PIBIC, em 2020/2021, sob a orientação do Prof. Dr. Rivaldo Capistrano Júnior.
} 


\section{PERcursos Linguísticos • Vitória (ES) •v. $11 \bullet$ •n. 29 • 2021 • ISSN: 2236-2592 • Dossiê temático $\bullet O$ texto na pesquisa e no ensino: conhecimentos, práticas e desafios na contemporaneidade •}

Messias Bolsonaro para governar o Brasil. No trecho do vídeo, o pré-candidato à prefeitura da cidade de São Paulo Guilherme Boulos defende que o dever de um Presidente, na área da saúde, é salvar vidas.

Como vimos anteriormente, a modalidade polêmica nasce a partir das relações intertextuais, e só se efetiva na interação entre sujeitos e no diálogo entre textos. Nesse sentido, a postagem motivadora teve origem a partir de uma notícia a respeito da entrega do pedido impeachment de Bolsonaro à Câmara de Deputados, por parte da oposição.

Ainda em relação à postagem motivadora, podemos observar que a página do UOL faz uso da intertextualidade por copresença (CAVALCANTE et al, 2020 e CAVALCANTE et al., 2021), como a citação do trecho em vídeo que demonstra partidos, entidades e movimentos sociais, entregando o pedido de impeachment do presidente do Brasil à Câmara. É a partir da utilização desse recurso que a polêmica se atualiza nessa postagem.

Em um segundo caso, a polêmica se atualiza a partir do pronunciamento televisivo na qual, políticos, entidades e movimentos sociais pedem a cassação do mandato de Jair Bolsonaro. Nesse contexto, os apelos intertextuais são de natureza muito mais ampla, porque correspondem a alusões, como referências vagas a diversos textos/situações inespecíficos que abordam a incapacidade administrativa e humana de governar o país.

E, por fim, a polêmica se atualiza na interação realizada por meio dos comentários da postagem reatiava, instaurando, assim, outra ocorrência intertextual por meio da metatextualidade, ou seja, o comentário de um texto por outro texto.

No que tange à análise da atualização da polêmica nos comentários, com respaldo em Amossy (2017), assumimos o posicionamento de que a Webnotícia, em si mesma, não instaura nenhuma dicotomização de uma interação polêmica. Isso ocorre nas trocas interacionais que acontecem em espaços de comentários, postagens reativas, nos quais os internautas assumem seus papéis sociais, ou seja, o de proponente, o de oponente e o de terceiro.

Feitas essas considerações, passamos à análise dos comentários.

Figura 02: Comentário 1 e comentários a comentários 


\section{PERcursos Linguísticos • Vitória (ES) •v. 11 •n. 29 • 2021 • ISSN: 2236-2592 • Dossiê temático $\bullet O$ texto na pesquisa e no ensino: conhecimentos, práticas e desafios na contemporaneidade •}

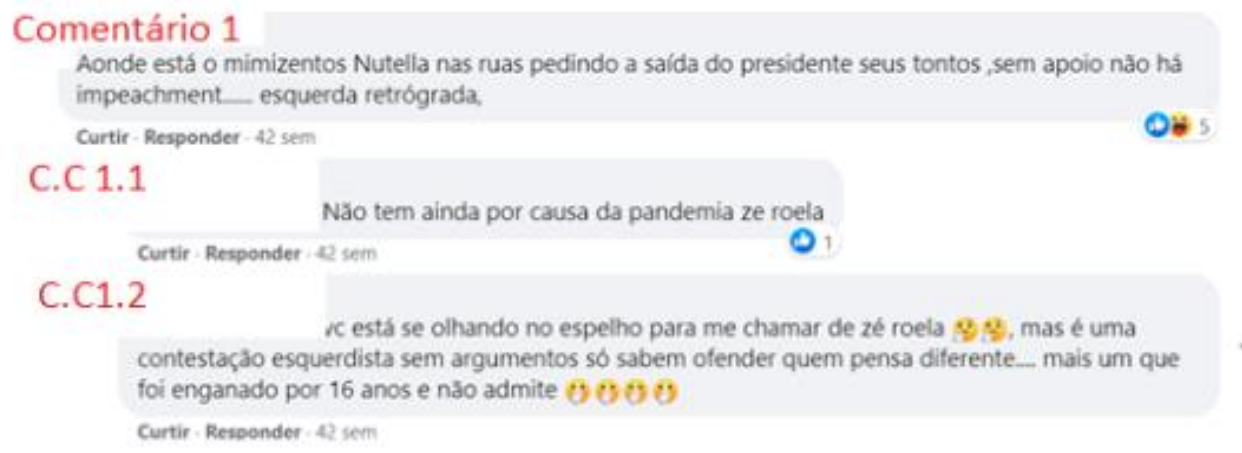

Fonte: https://www.facebook.com/21539158238/videos/2630608990540699/

A imagem 02 contém uma unidade de interação, na qual C1 faz um comentário, C.C. 1.1 (@C1) faz uma réplica e C.C.1.2 (@CC1.1), uma tréplica.

Podemos notar que a caraterística da dicotomização se evidencia nos comentários com a radicalização em polos opostos, na qual temos internautas que assumem diferentes posicionamentos. Um dos lados dessa polarização assume a extrema esquerda e o papel de Proponente e o outro, a extrema esquerda e o papel de Oponente.

Assim, C1 se lança como proponente da questão que norteia o embate: a falta de articulação da esquerda com líderes de outros partidos políticos, segundo C1. Podemos destacar, nas escolhas linguísticas de CI, uma orientação avaliativa de caráter negativo na qual por meio da introdução referencial "o mimizentos Nutella" - isto é, aquele que reclama muito, que vive resmungando, chorando - e do referente "esquerda retrógrada" o internauta busca desqualificar o oponente.

Por sua vez, C.C 1.1 responde ao comentário de C1 e assume o papel de oponente, argumentando que a pandemia inviabilizou uma possível aliança da oposição com dissidentes do bolsonarismo e por meio da anáfora "ze roela" busca desqualificar $\mathrm{C} 1$. A escolha lexical feita por C.C 1.1 evidencia o propósito de instigar a polêmica, tendo em vista o uso de palavras de cunho mais agressivo.

Já em C.C 1.2 há uma tréplica em que há uma desqualificação do adversário, no caso o adversário C.C 1.1, quando há a resposta: "vc está se olhando no espelho para me chamar de ze roela". O usuário enfatiza mais essa desqualificação quando chama o outro de "esquerdista", que é visto socialmente como um sentido ruim, por representar um extremo. Dando seguimento às ofensas, o usuário diz que o outro foi enganado por 16 anos, que, no caso, foi enganado pelo lado esquerdo. 


\section{PERcursos Linguísticos • Vitória (ES) •v. $11 \bullet$ •n. 29 • 2021 • ISSN: 2236-2592 • Dossiê temático $\bullet O$ texto na pesquisa e no ensino: conhecimentos, práticas e desafios na contemporaneidade •}

Figura 03: Comentário 02 e comentários a comentários

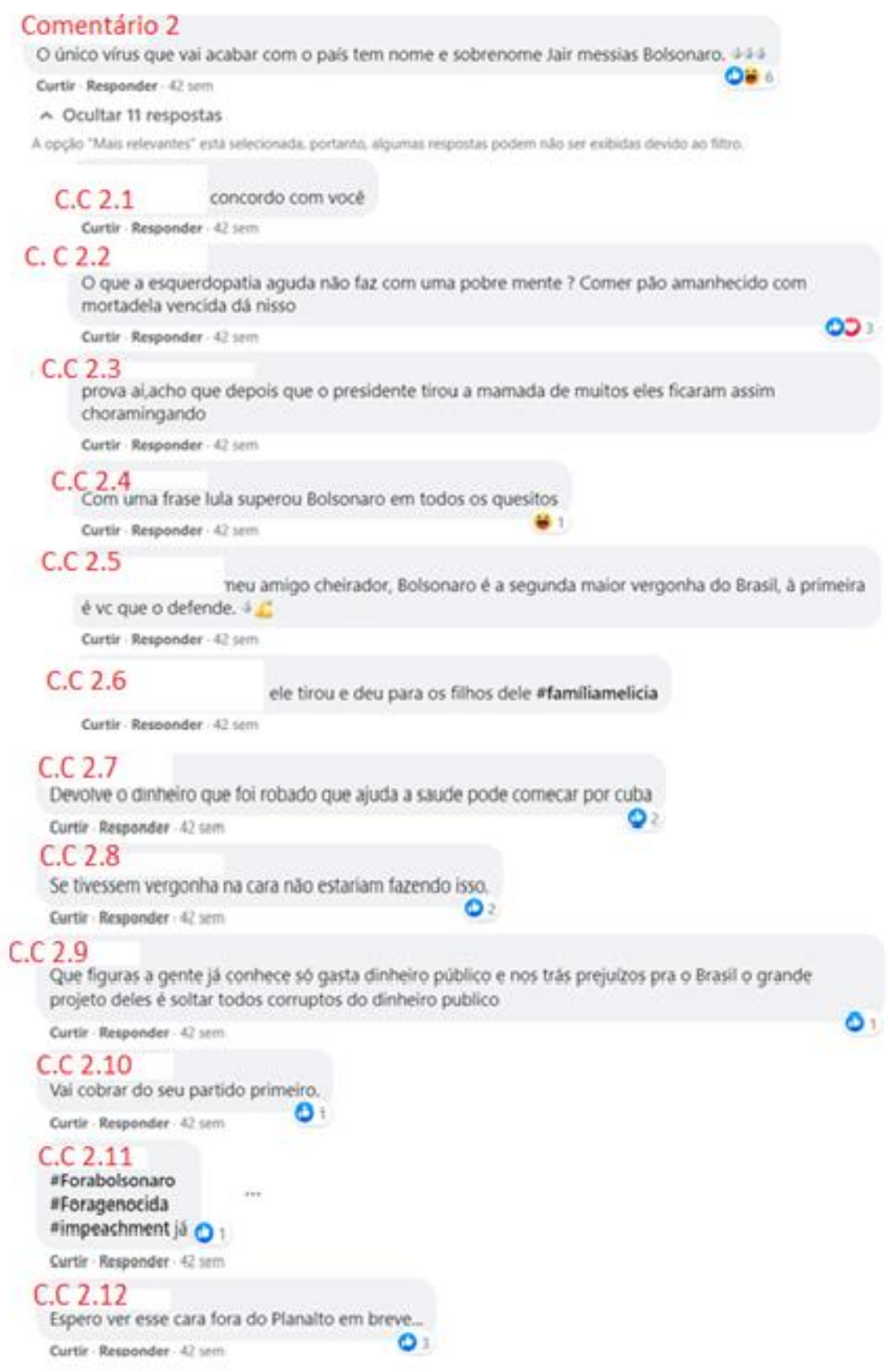

Fonte: https://www.facebook.com/21539158238/videos/2630608990540699/

No comentário 2, o internauta introduz o referente Jair Messias Bolsonaro, que, comparado a um vírus a ser eliminado, é considerado a raiz de todos os males que assolam o Brasil. Ao comparar o presidente a um vírus a ser eliminado, o internauta está fazendo intertextualmente alusão ao Coronavírus, agente causador da Covid-19. Isso contribui para a materialização do antagonismo nos comentários que se seguem. 


\section{PERcursos Linguísticos • Vitória (ES) •v. $11 \bullet$ n. 29 • 2021 • ISSN: 2236-2592 • Dossiê temático $\bullet O$ texto na pesquisa e no ensino: conhecimentos, práticas e desafios na contemporaneidade •}

Assim, esse comentário é desencadeador de uma interação polêmica em que atores sociais se polarizam em dois agrupamentos por identificação, os quais, por sua vez, atualizam visões dicotomizadas: um de opositores do presidente; outro de apoiadores.

No comentário a comentário 2.1, o internauta expressa concordância com o que foi dito no comentário 02 , mantendo a visão sobre o referente focalizado.

No comentário a comentário 2.2, os referentes "esquerdopatia aguda" e "pão amanhecido com mortadela vencida" buscam deslegitimar o grupo opositor, rebaixando-os e até buscando colocá-los fora da disputa. Para tanto, o internauta faz uso do recurso da intertextualidade para fazer alusão a uma expressão muito utilizada por simpatizantes da extrema direita para se referir aos petistas. $\mathrm{O}$ termo está ligado a um boato de que aos militantes petistas era dado sanduiches de pão com mortadela nos protestos e passeatas. Assim, nesse comentário, temos uma remissão operada pela parte verbal ao termo "mortadela".

Desse modo, por meio dessas expressões referenciais, o internauta, em C.C. 2.2, busca insultar o grupo adversário, invalidando o ponto de vista dos internautas, expresso no comentário 02 e em C.C 2.1. Trata-se do ataque ad hominem (AMOSSY, 2017), que busca desacreditar o grupo de opositores ao governo, no caso, apoiadores e eleitores do Partido dos Trabalhadores (PT).

O comentário a comentário 2.3 é uma réplica ao que disse o internata no Comentário 2 e faz, por meio da anáfora "o presidente", menção a Jair Bolsonaro. Por sua vez, o referente "mamada" estabelece uma relação intertextual por alusões amplas e desqualifica o grupo de opositores ao governo, referente inferencialmente instaurado por meio da anáfora indireta "eles".

A postagem reativa C.C. 2.4 introduz o referente Lula, qualificado como superior ao Bolsonaro, que, inferencialmente, é considerado inferior, o que constitui numa estratégia de desprestígio.

Nessa sequência, o comentário de C.C 2.5 promove a inflamação da interação polêmica, na qual o proponente estabelece uma desqualificação do adversário, sendo também uma violência ad hominem, visto que chama quem defendeu o presidente da república Jair Bolsonaro de cheirador, sendo contrário a um posicionamento favorável ao atual presidente.

Em C.C 2.6, há um posicionamento contrário à família de Bolsonaro, chamada de familiamilicia.

$\mathrm{Na}$ sequência, a análise dos próximos comentários também põe em evidência e atualizam o embate político entre duas frentes ideológicas: apoiadores do Presidente (C.C.2.7, 


\section{PERcursos Linguísticos • Vitória (ES) •v. 11 •n. 29 • 2021 • ISSN: 2236-2592 • Dossiê temático $\bullet O$ texto na pesquisa e no ensino: conhecimentos, práticas e desafios na contemporaneidade •}

\section{C.C. 2.8 , C.C. 2.9 e C.C. 2.10 ) e contrários a ele (C.C. 2.11, C.C. 2.12).}

Em C.C. 2.7, há uma crítica ao Partido dos Trabalhadores (PT) na medida em que esse concentrou verbas para Cuba na vez de seus mandatos. Portanto, esse proponente se coloca a favor do presidente Jair Bolsonaro.

Em C.C. 2.8, por meio do dêitico textual "isso", que, do ponto de vista textualdiscursivo, não só faz o apontamento ao vídeo, mas também encapsula seu conteúdo, há uma adesão ao dito em C.C. 2.7, uma vez que as pessoas que estão aspirando ao impeachment não têm vergonha na cara.

Em C.C. 2.9 e C.C. 2.10, novamente, há uma adesão ao dito em C.C. 2.7 e uma busca a desqualificação do interlocutor.

Já em C.C. 2.11, temos uma sequência de hashtags, referentes que fazem alusão a um posicionamento favorável ao que foi proposto no vídeo: \#forabolsonaro, \#foragenocida, \#impechment já. As hastags nos dão pistas para a formação da polarização no espaço público.

E, com o mesmo posicionamento do comentário a comentário 2.11, temos o comentário a comentário 2.12 que faz uma afirmação que condiz com um posicionamento favorável ao que se tem no vídeo, quando esse diz: "Espero ver esse cara fora do Planalto já".

\section{Considerações Finais}

Neste trabalho, buscamos evidenciar a interface possível entre a Linguística Textual e a Teoria da argumentação nos discursos (AMOSSY, 2017, 2018). Nesse sentido, critérios de análise da Linguística Textual, tais como a referenciação e a intertextualidade, podem ser convocados para a análise da modalidade polêmica.

Os resultados apontam que i) as interações polêmica se dão nos comentários, ou seja, nos textos que comentam o a postagem motivadora; ii) os referentes constituem-se em relevantes estratégias para deflagrar a violência verbal, evidenciando a dicotomia entre os pólos em discussão, iii) a modalidade polêmica tem origem a partir das relações intertextuais e só se concretiza com base no diálogo entre textos, uma vez que os comentários que atualizam teses dicotômicas citam, parafraseiam, aludem a outros textos.

Além disso, a violência verbal tem a função de reforçar e de aglutinar grupos antagônicos aos quais pertencem cada internauta; no caso, opositores e simpatizantes de Bolsonaro. Esse antagonismo engendrado a partir de pontos de vista dicotômicos tem origem em fatos ocorridos e em relações intertextuais. 


\section{PERcursos Linguísticos • Vitória (ES) •v. $11 \bullet$ n. 29 • 2021 • ISSN: 2236-2592 • Dossiê temático $\bullet O$ texto na pesquisa e no ensino: conhecimentos, práticas e desafios na contemporaneidade •}

\section{Referências}

AMOSSY, Ruth. A argumentação no discurso. São Paulo: Contexto, 2018.

AMOSSY, Ruth. Apologia da polêmica. São Paulo: Contexto, 2017.

AMOSSY, Ruth. Argumentação e análise do discurso: perspectivas teóricas e recortes disciplinares. Tradução Eduardo Lopes Piris e Moisés Olímpio Ferreira. EID\&A, Ilhéus, 1, Nov. 2011.

AMOSSY, Ruth. As modalidades argumentativas do discurso. In: LARA, Gláucia; MACHADO, Ida; EMEDIATO, Wander (Orgs.). Análises do discurso hoje, vol. 1. Rio de Janeiro: Nova Fronteira, 2008, p. 231-254.

CABRAL, Anal Lúcia Tinoco. Violência verbal e argumentação nas redes sociais: comentários no Facebook. Calidoscópio, v. 17, p. 416-432, 2019. Disponível em: $<$ http://revistas.unisinos.br/index.php/calidoscopio/article/view/cld.2019.173.01>. Acesso em: 28 set. 2021.

CABRAL, Anal Lúcia Tinoco; LIMA, Nelci Vieira de. Interações conflituosas e violência verbal nas redes sociais: polêmica em comentários no Facebook. (Con)Textos Linguísticos, v. 12, p. $\quad$ 39, 2018. Disponível em: $<$ https://periodicos.ufes.br/contextoslinguisticos/article/view/20626>. Acesso em: 28 set. 2021. CHARAUDEAU, Patrick. Discurso das mídias. São Paulo: Contexto, 2015.

CAVALCANTE, Mônica Magalhães. Revisitando os fatores de textualidade. II Ciclo de Conferência GEPEL-UFF. YouTube. Publicado pelo canal GEPEL-UFF, 2021. 1 vídeo (1h36min). Disponível em: $<$ https://www.youtube.com/watch?v=Ji_jw8Ld-jc $>$. Acesso em 29 set. 2021.

CAVALCANTE, Mônica Magalhães et al. O caráter interacional e intertextual da argumentação polêmica. Revista (Con)Textos Linguísticos, v. 15, n. 31, p. 48-65, 2021. Disponível em:

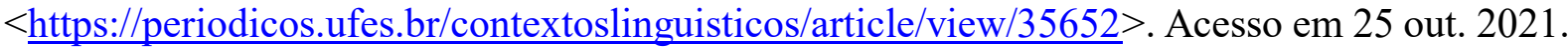
CAVALCANTE, Mônica Magalhães et al. Linguística Textual e Argumentação. Campinas, SP: Pontes Editores, 2020. 
PERcursos Linguísticos • Vitória (ES) •v. 11 •n. 29 • 2021 • ISSN: 2236-2592 • Dossiê

temático $\bullet O$ texto na pesquisa e no ensino: conhecimentos, práticas e desafios na contemporaneidade •

CAVALCANTE, Mônica Magalhães; MACEDO, Patrícia Sousa Almeida de. Estratégias de textualização na polêmica sobre culturas agrícolas no Brasil. Entre palavras, Fortaleza, v. 9, p. 303-320,

n.

1, jan-abr/2019.

Disponível

em:

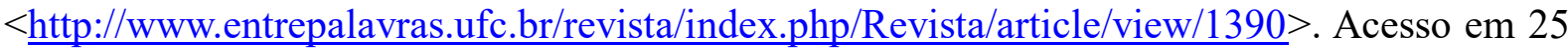
out. 2021.

CAVALCANTE, Mônica Magalhães et al. Coerência e referenciação. In: MARQUESI, S. C.; PAULIUKONIS, A. L.; ELIAS, V. M. (Orgs.). Linguística textual e ensino. São Paulo: Contexto, 2017. p. 91- 107.

KOCH, Ingedore Grünfeld Villaça. ELIAS, Vanda Maria. Escrever e argumentar. São Paulo: Contexto, 2016.

PERELMAN, Chaim \& OLBRECHTS-TYTECA, Lucie. Tratado da argumentação: a nova retórica. Trad. Maria Ermantina de Almeida Prado Galvão. 4.ed. São Paulo: Martins Fontes, 2020

UOL. Oposição entrega pedido impeachment de Bolsonaro à Câmara de deputados. Disponível em: https://www.facebook.com/21539158238/videos/2630608990540699/. Acesso em: 17/03/2021. 